\title{
THE MURAL DESIGN DERIVED FROM HERITAND ITS IMPACT ON THE DEVELOPMENT OF COMMUNITY CULTURE
}

\author{
ASMAA MOHAMED ALI SHAHIN \\ Associate Professor of Design - Former Head of Art Education Department - \\ Faculty of Education - Suez University \\ Asmaa.Shahin@edu.suezuin.edu.eg
}

\begin{abstract}
Culture for the individual is related to knowledge, but culture for society is related to social characteristics far from being cognitive because it results from the individual and society's perception of science and knowledge in various areas of life. If development, in its essence, works to enhance the levels of coexistence among people and advance the lives of individuals in society, then development efforts can never be separated from the cultural formations of society. Culture plays a pivotal role in the development process. Through distinctive environment and society such as the city of Suez, with its rich history and heritage, so, what is the difficulty of designing mural derived from that heritage to affect the different categories of society in specific location in this city?
\end{abstract}

\section{$\underline{\text { Key words }}$}

Wall design- Heritage- development-culture-the society

\section{INTRODUCTION}

Art of street murals (STREET ART) is one of the most important contemporary arts that spreads in all countries of the world. It derived from heritage of those peoples and their ideas, loaded with a strong aesthetic message with a character that excites People and a very important cultural message for these People categories and may be a documentation of the history, present and future. 
If the mural is art work drawn directly on wall, ceiling, or other large permanent surfaces, then the most important characteristic of that wall painting is how it harmonizes with the architectural facade drawn on it. It may be building façade, cover walls of tunnel, wall specially erected for it, in street, park, or entrance to town, city or square. Such art has sociocultural message to the members of society. Most countries, nowadays, have become aware of the importance of this art, so they began to multiply it and spread it in more than one country, and for more than one goal and purpose.

Through distinctive environment and society such as the city of Suez, with its rich history and heritage, so, what is the difficulty of designing mural derived from that heritage to affect the different categories of society in specific location in this city?

\section{Research Problem:-}

Can the constructive values of a heritage mural design positively affect the development of a community's culture?

\section{Research Hypotheses}

1. There is positive relationship between the constructive values of murals design derived from heritage and developing the culture of societies.

2. There is positive relationship between the content of murals design and the development of mutual culture between different societies.

\section{Research Aims}

- Developing the society culture through constructive values of murals design derived from the heritage.

\section{Research Importance:-}

- The structural systems of murals derived from the heritage achieve sustainable development of the society's culture.

- Highlighting the importance and gravity of role that street murals play in shaping the awareness of the recipient. 
The possibility of crossing street murals as visual language to establish dialogue with different categories of society

\section{Research Methodology:-}

\section{Research Experimental Location:}

Suez City - Students of Art Education Department, Suez University.

The word "MURAL" is derived from Latin "murus" which means "wall", and it can be artistically defined as a construction of colored artwork or technically executed on a wall surface. A mural Design is also known as drawing that is applied directly to surface of wall, ceiling or that have been drawn on canvas or wood and fixed after that on wall.

The mural designs are among the oldest forms of human art found in cave paintings in most places where ancient humanity was located around the world. Art of all kinds was way for primitive Man in prehistoric times to express his life and comes to him from ideas about the world around him and other things. Therefore, he trusted his beliefs, rituals and activities through. He his simplified drawings, and he simulated what his environment contains on the walls and ceilings of caves, taking advantage of the irregular nature of wall surfaces, which helped him in developing his simulation of reality in his drawn forms, thus he was the first designer of murals in history.
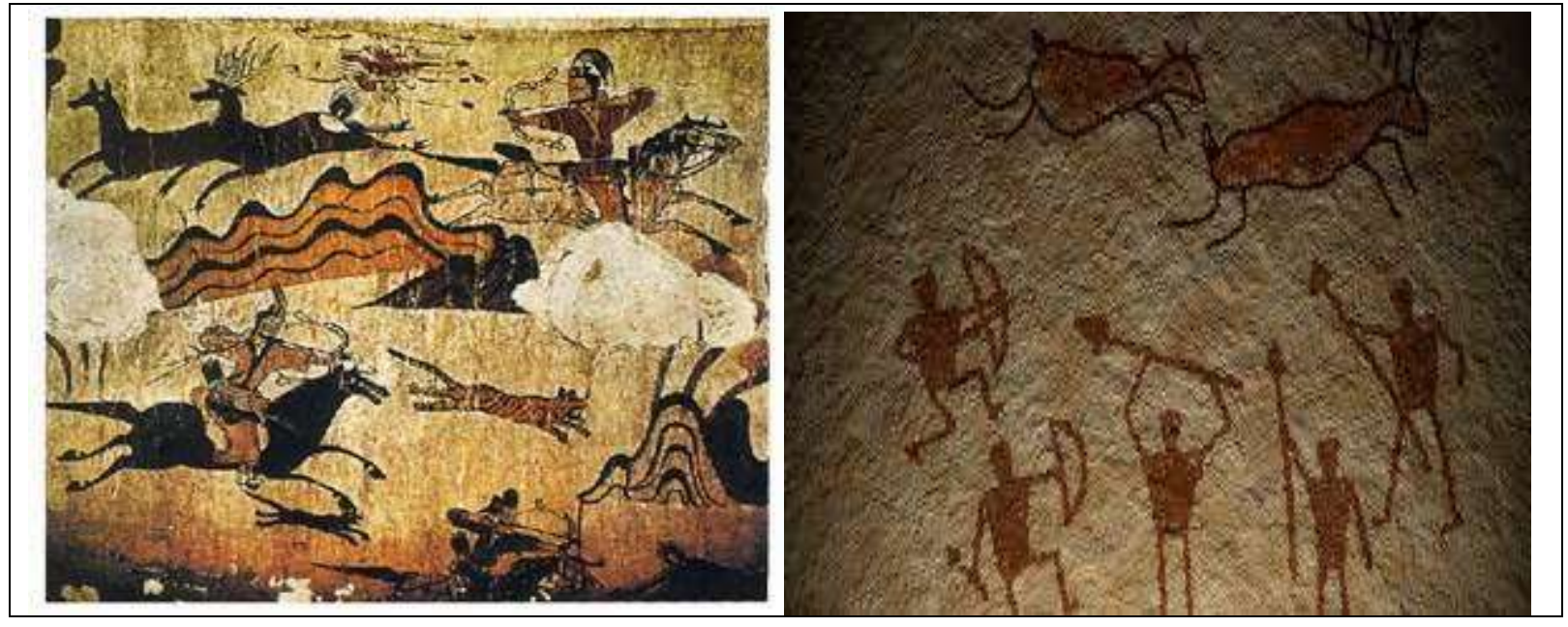


\section{Figure (1) Drawings on cave murals}

The first man painted before he knew writing, so his murals design were his alternative reading language for speech since his inception. Through murals, he found a refuge to express himself and narrate his history.

The murals, in general, embody activities of the people in a civilization, by embodying specific event that narrates different scenes from their lives from hunting, family life, wars and trade trips even religious and funeral scenes.

It represents linguistic visual medium that artists speak to the public and authority, as it plays a role in creating public awareness of specific issues, in addition to the function of social and political criticism, as well as strengthening cultural and societal identities.

The mural painting of the ancient Egyptians played an important role in conveying the idea of religion and bringing it closer to the minds of people and creating a spiritual atmosphere that helps in performing the rituals. Ancient Pharaonic temples and tombs were decorated with drawings with themes that represent life aspects and religious rituals.

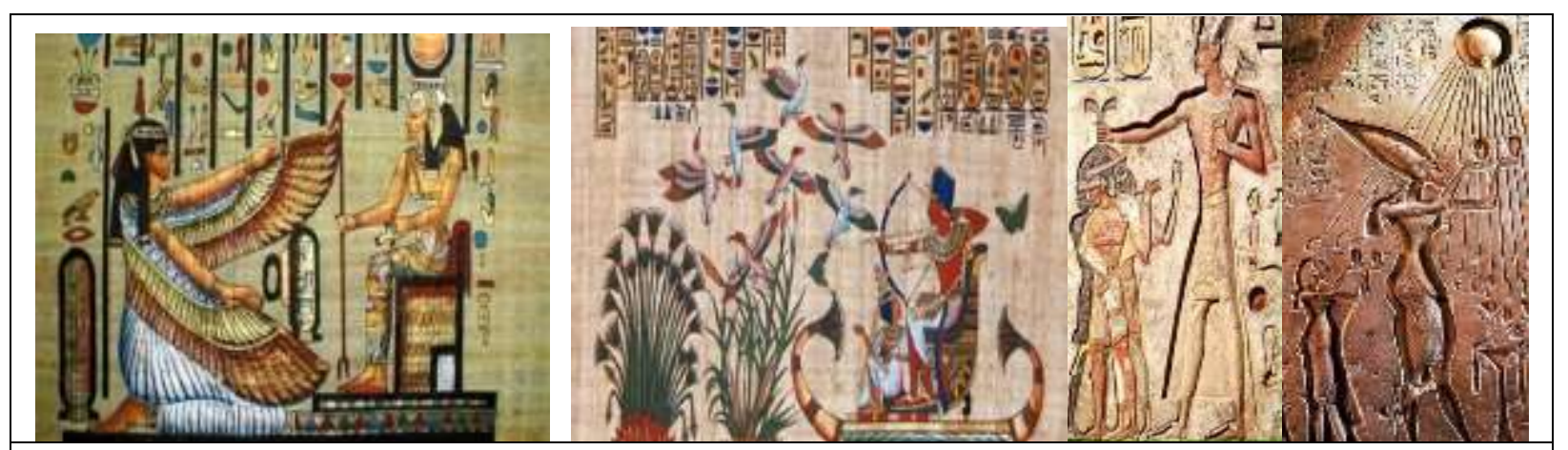

Figure (2) Designs of some murals in the Ancient Egyptian civilization

The successive civilizations in Mesopotamia also created artistic drawings that reflected aspects of life in various aspects, religiously, socially, culturally, militarily and scientifically. Murals were also spread in most countries of the Mediterranean as well as in Crete island and the ancient Greek civilization, which was influenced in its beginnings by the Egyptian civilization. 
In the Roman era, drawings spread on the walls and floors of palaces, and the design of murals with its various techniques became prevalent in interior decoration. This era was characterized by the interest in the emergence of psychological and emotional expressions on the faces, and surrounding the pictures with decorative painted frames.

The elements of the wall design in the Byzantine era were a mixture between Greek art and the arts of the East, and the Byzantine mosaic decoration showed a greater connection with the organic architectural form, so glass mosaic murals complemented the architecture of Byzantine churches.

Murals of the Islamic era: The murals of the Islamic era were designed uniquely from other arts that preceded it, through the philosophy of the Islamic faith. The Muslim artist mastered the use of wall decorations (which do not contain drawings), digging and grafting with other materials, so the art of securitization (arabesque) and using of intertwined geometric shapes, coordination and drafting them in exquisite artistic forms, in addition to plant motifs with their wavy branches, calligraphy motifs, specifically the Kufic and Naskh calligraphies.

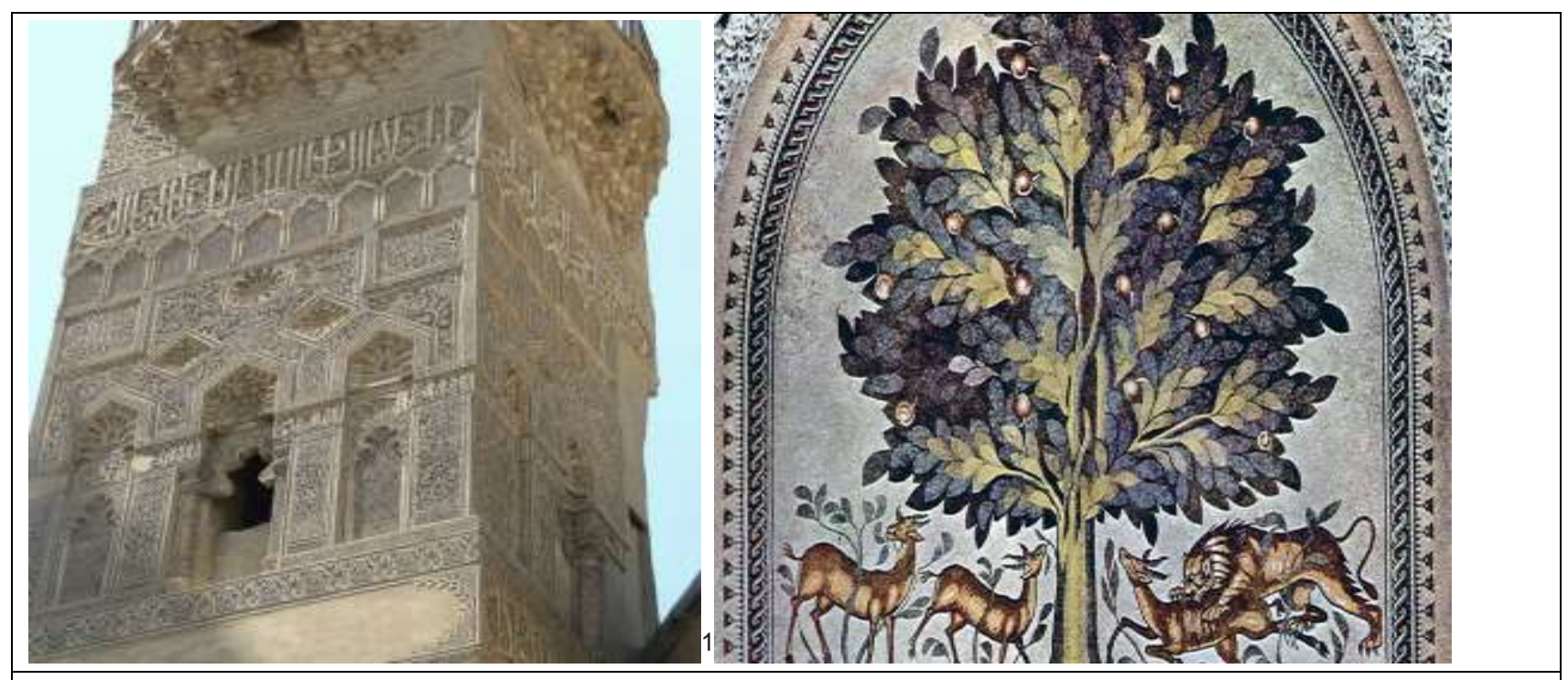

Figure (3) Part of dome of the Mosque of Mohamad Ibn Kalawun - the largest mosaic mural in the Middle East and the world, one of the pearls of the Umayyad 


\section{dynasty in the $8^{\text {th }}$ century AD}

The Muslim artist was famous for abstraction. He used the floral decorative unit, stripped it of its natural form and transformed it into geometric shapes that give a sense of continuity and infinite, and he relied on the philosophy of central oneness and decorations extending to infinity.

Modern murals and graffiti art: There are many artistic and varied styles in our current era between the use of oil colors, acrylics, sprays of all kinds, dyes and mosaics, and their goals have diversified and entered the field of interior and exterior design, decorating homes, spaces and public squares, and varnished to protect them from ultraviolet rays.

The term "graffiti", which refers to drawing, engraving or writing on the walls using dyes and color sprays, has spread. The use of materials and tools in the field of wall design and the investment of these various plastic media in the implementation process related to the heritage data, so that art reflects its aesthetic, cultural belonging role on society. Thus, we will reach a deeper concept of contemporary wall design, which contributes in enriching cultural values and the rooting of identity in a manner commensurate with the $21^{\text {st }}$ century. Whereas the development of the mural design was an imperative necessity to transmit the philosophy of the age and link the past with the present. The artist had to lead change in the plastic art vision and his expressive and constructive systems to design murals drawn from heritage and history in contemporary aesthetic style as a language of dialogue to make mobility for the ordinary viewer of all ages. Cultures and backgrounds were as way for artists to communicate with the audience, and communicate their opinions, outlook and needs.

We now are dealing with production of contemporary murals while preserving the cultural identity, so we must be aware that the philosophy of art in our society depending on the intellectual background of the environment that helps the artist in determining the path of his artistic creativity and in protecting his artistic personality from imitation. To represent that bond in pursuit of work of art as an educational, cultural and national responsibility that has roots in the depths of society. Through this study, the researcher is trying to monitor her experiment and artistic 
production in which she devoted her efforts in order to develop environmental awareness, and raise the level of aesthetic taste. She address the deficiencies in the environment and she address everything that may disturb the aesthetics of art, so that art be based on solid roots and is based on an aesthetic philosophy issued from its environment to show the façade, the civilization of society is established on its historical origins and societal concepts.

The art of mural design is considered the first art that expresses the human need for that value pattern in which the culture is reflected in the consciousness of individuals and categories in the form of an integrated system of spiritual, cognitive, aesthetic and ethical values. Undoubtedly, the difficult equation that the art of design seeks to achieve throughout its history in combining the development of Thought, beauty and utility, which is the internal law of things and their logical constructions that operate within a precise systematic sequence. These are the problematic issues that the Man is still in his constant endeavor to develop all things around him by discovering new theories and materials. As result of the design dialogue with that knowledge, new intellectual perspectives and theoretical standards were formed, through which Man was able to obtain an enormous abundance of the creative process at the level of art and beauty. Design as art no longer means those creative craft skills, despite their utmost importance as a translation to transform theoretical ideas into facts that are at the core of the human experiment

It is necessary to match the murals design with the suggestive requirements of function of the building, and role of the murals in spreading awareness of different cultures and arts, in addition to achieve aesthetic values, developing the sense and taste of the recipient, or their roles in decorating, beautifying buildings, and link facilities with their functions and history.

\section{Research Experiment:}

The research experiment in the Egyptian city of Suez is concerned with the history of struggle and struggle that has endured its nature of mountains, open skies and desert environment in addition to the Suez Canal. The 
experiment here is about the construction of the mural design, its cultural and cognitive impact on the recipient of different age and cultural categories.

In the beginning, questions were asked about the location of the mural in the environment and the type of architectural structure that the mural will be applied to - its goal - the occasion for it - the target community category. Wall painting differs in nature from all other forms of art, as it is organically linked to architecture. The use of design, structural values, and local treatment can radically change the sense of the spatial proportions of the building. Thus, the mural is the only three-dimensional form of the drawn design, for its ability to modify the area applied to it.

The most important steps that must be taken into account in implementing the wall design: -

First: Defining the murals into three groups: -

1- Murals inside the facility within the boundaries of the building (whether in the entrance - or in a closed hall - corridor)

2- External murals meaning outside the building, but within the boundaries of the facility (official - entertainment - sports). The target category is determined in the type of society visiting that facility.

3- Murals outside the facility boundaries on the street. The target category is defined to all cultural and age categories in society.

Consideration should be given to the type of audience hesitant about the place and the extent of their understanding of the wall design.

Second: - Determining the positive value learned from the mural (cultural - educational - social - functional historical in addition to the aesthetic value)

Third: - Put preliminary planning for the design and identification of design elements derived from heritage, historically, socially, or from the environment. 
Fourth: Developing its design ideas and various solutions, taking into account the proportions of the place and the level of its height in relation to the architectural site.

Fifth: - Determining the artistic style used

Sixth: - Evaluating ideas and choosing the best solution for what is required

Seventh: Determining the structural design system in line with the architectural building applied to it.

Fifth: - Determining the structural foundations used in the design.

Sixth: - Modifying and developing the design according to the available data.

Seventh: Presenting the visualization of the final design.

Eighth: - Determining the required materials, tools and techniques used, so the raw materials technology must be compatible with the place and the philosophy of wall work..and the material used in the wall work must also bear the weather factors, so it needs to be of a high degree of hardness and durability.

Ninth: Determine the schedule for the work plan.

Tenth: Determining students' work groups, each according to capability and how they can integrate together through the organization of the implementation mechanism.

Eleventh: - To start implementation, taking into account the structural and color value of the wall work and its connection with vision and lighting

A- First Category: - Murals inside the facility within the boundaries of the building (whether in the entrance - or in a closed hall - corridor) 


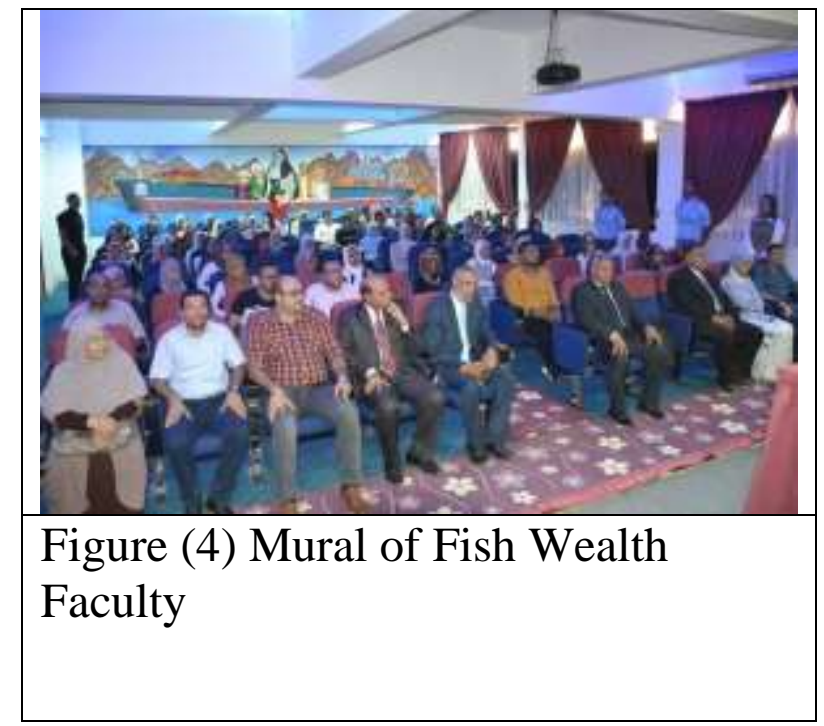

First experiment: Figure (4)

\section{First: Description:}

Place: The main hall in the Faculty of Fish Resources

Elements: Defining elements that symbolize and express the faculty with its various departments: Mountains - Water - Cargo Ship - Different community categories (fisherman, farmer, Nubian, Upper Egypt citizen and university student) - The main symbolic element of Egypt and national unity

Area: The façade of the inner hall 7 X 5 meters, direct application to the wall.

Materials and tools: Oil colors - Number of students: four students - Time period: three weeks and one preparation week.

\section{Second: - Determining the positive value learned from the mural.}

Cultural values: the symbolism of expressing different categories of society

- the symbol of the child and the science that it is the future - giving the value of national unity in the main element of the design. 


\section{Third: - Initial design planning and identification of design elements derived from society and the environment.}

Fourth: Developing its design ideas and solutions while taking into account the proportions of the place and the level of its height in relation to being inside a hall, the vision of the wall work at the level of the view. The space available in front of him to see the boundaries of the hall is 8 meters.

Fifth: - The used artistic style: is realistic and symbolic.

Sixth: - the structural and aesthetic values: -

- The structural system is central, axial or vertical, represented in the main element, which gave confirmation of the cultural content. The horizontal position of the ship with irregular repetition of mountains in the horizontal direction achieved stability with movement with coherence and axial balance. The rhythm through the repetition of characters on both sides of the main character descending and the mountains in the background with free repetitive rhythms, the strength of black and white in the main element and the harmony of the colors of the design with colors of the hall and lighting. 


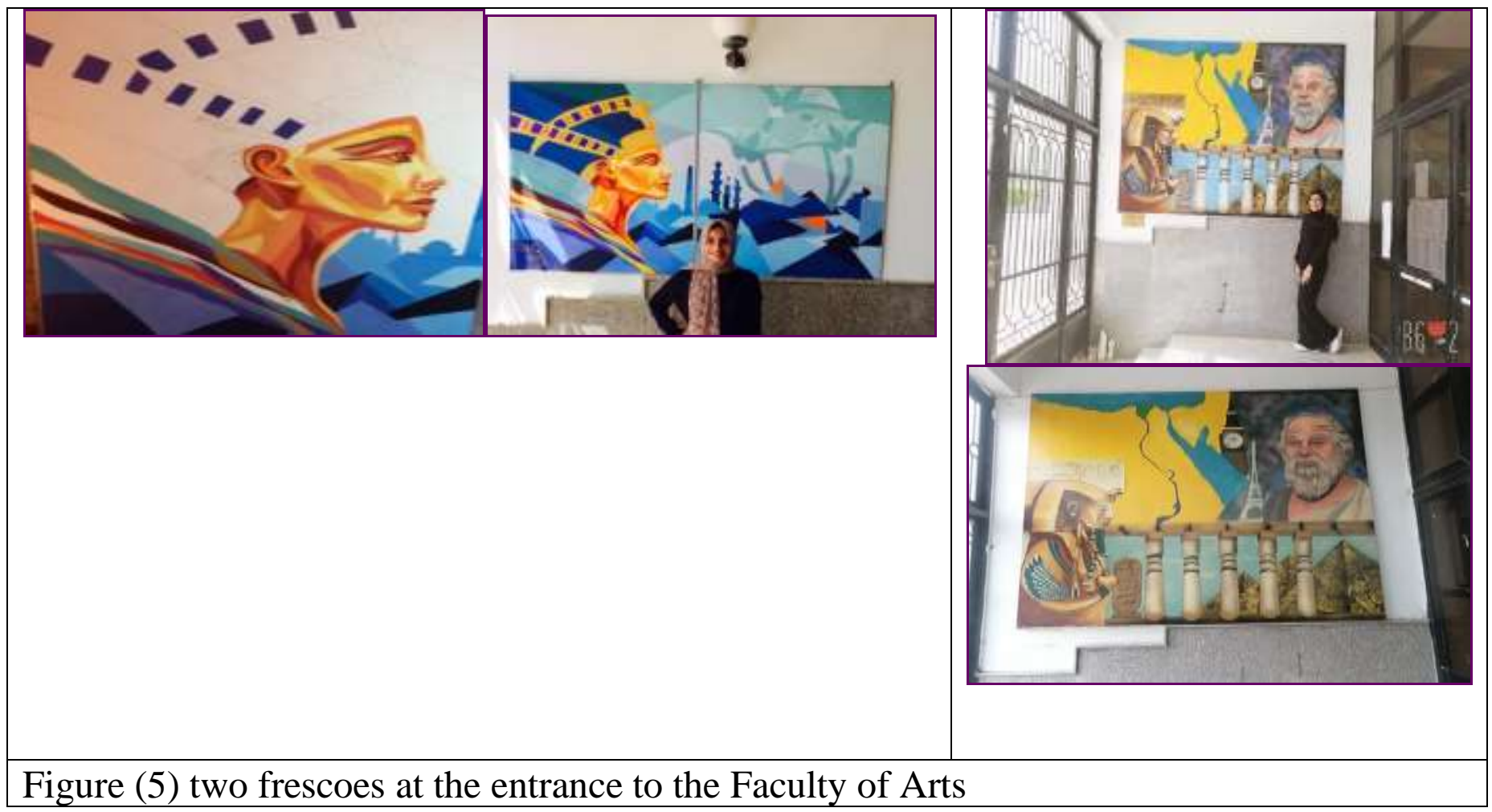

Second Experiment:

First: Characterization: -

Location: Entrance to the Faculty of Arts, a separate mural.

Elements: A- the pyramids - - Egyptian map - Socrates - Tutankhamun temple - Pharaonic cartridge - Eiffel Tower - London clock.

B - Nefertiti - domes and minarets - lotus flowers.

Area: the size of one mural is $2 \times 2.5$ meters.

Materials and tools: A - Duco color sprays with oil paints.

B- Oil colors.

Number of students: two students 
Second: - Determining the positive value learned from the mural (cultural aesthetic and educational)

A- The development of culture with personalities and symbols Socrates philosophy, psychology, language departments, the history department, the geography department, the association of symbols with being the faculty and this is the latest cultural and cognitive movement among students of all specializations.

B- The contemporary analytical vision of the Egyptian heritage emphasized the aesthetic taste and the emphasis on raising the level of the viewer's vision. We note that the two paintings complement each other despite the difference in style and are linked with the function of the place and the achievement of aesthetic and cultural values (5-a) (5-b)

Third: - Initial design planning and identification of design elements derived from heritage, history, social, or from the environment.

Fourth: Developing its design ideas and various solutions, taking into account the proportions of the place and the level of its height in relation to the architectural site. The location of the vision of mural work at the level of the view and higher than the level of vision and the area available in front of total vision of the mural is 4 meters away

. Fifth: - The artistic style used is abstract in Nefertiti's painting - Expressive in Socrates' painting.

Sixth: - The structural and aesthetic values

A-The structural system is characterized by the overlap of elements between the horizontal direction of the columns with the direction of the elements in a vertical direction with the diversity of movement with stability. The Socrates element is direction of the statue of Tutankhamun with the diversity of the place and the feel of the pyramids. Equilibrium and varied rhythms between regular in columns or free in other elements.

B-Abstraction and analysis of Nefertiti's head and background, placing it in the two-thirds and the direction of her head into the work, the color rhythms 
and the strength of linear rhythms achieved movement, coherence and chromatic balance.

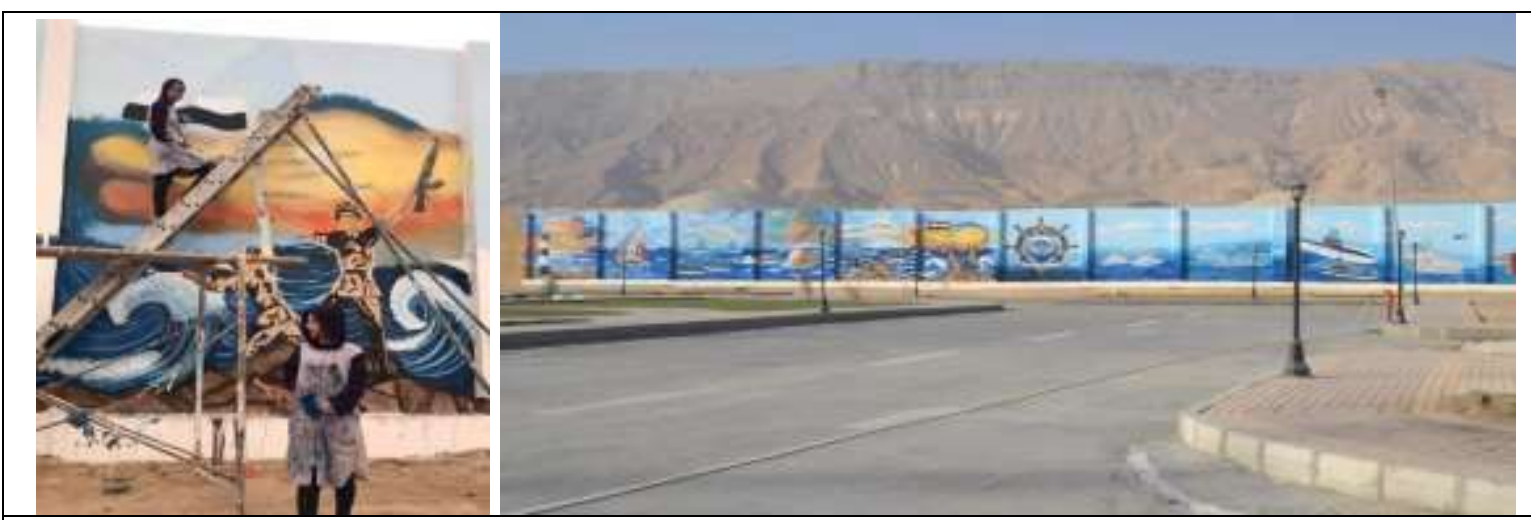

Figure (6) the mural of the maritime history of Egypt

2- External murals outside the building, but within boundaries of the building (official)

The type of society visiting that building determines the target category: -

Third experiment Figure (6): -

First: Description:

The place: The naval base is frescoed on a part of the wall surrounding the base on the inside, with mountains

Elements: the lighthouse - the boat - the Egyptian soldier - the divers - the launch - the submarine - the Mistral - the rocks - the waves - the clouds.

Space: 11 parts.

Materials and tools: oil colors - sponges - oil brushes.

Number of students: 10 students.

Second: - Determining the positive value learned from the mural (cultural developing patriotic sense - historical - aesthetic) 
Third: - Initial design planning and identification of design elements drawn from history and the environment.

Fourth: Developing its design ideas and various solutions while taking into account the proportions of the place, as the wall is part of the surrounding nature, including mountains in the background and the sky stretching, and its height in relation to the architectural site is part of the mountains.

Fifth: - Artistic style used is Expressive.

Sixth: - Evaluating ideas and choosing the optimal solution for what is required. The various proposed methods were evaluated from an abstract style to a realistic style, with adding the lighthouse place in the foreground and the centralization of the artwork by placing the logo in middle.

Seventh: - the structural and aesthetic values

The structural system depends on the centrality around a vertical axis to separate two periods. The design achieved the values of unity and interdependence despite the diversity of elements through the background and color and the juxtaposition between the elements. Removing the boundaries of each part to be part of the wall painting that rises and falls from the various elements - achieving the various movement through the modes Elements from vertical to tilt to horizontal with the movement of soldiers, divers, stones, waves and clouds. The diversity of the positions of the elements and their directions achieved various kinetic rhythmic values. The balance of the distribution of the blocks with the different places and directions, with the achievement of the chromatic balance, values and high chromatic intensity within the painting as a whole the proportion and terms of dimensions. The elements are the depth of the painting and with each other and with the size of the mural as a whole. 
Third: - Initial planning for the design and defining the design elements derived from (society - the environment).

Fourth: Developing its design ideas and various solutions, taking into account the proportions of the place and the level of its height in relation to the architectural site.

Fifth: - Applied artistic style: abstract - and influential

Sixth: - Evaluating the ideas and choosing the best solution for what is required. A brainstorming session was conducted that included Colonel Ahmed, the village director and the lieutenant, with the students, and the session was conducted until the optimal solution was reached in a manner consistent with the mural space and its function as a facade of the village, its area, aesthetic values and social influence through it.

The second mural was much easier, as it consisted of selecting the elements and then selecting the constructivism of the design as a whole, through the juxtaposition and movement of the various elements.

Seventh: - Structural and Aesthetic Values

- The structural design system corresponds to the architectural structure to which the main element is applied in the main part of the building and facing the gate, in order to achieve the golden point in construction of the design with repetition of design elements from the abstract fish, but in a direction opposite to the path of eye movement. Emphasis on the horizontal ground line of interconnectedness between the elements by repeating plants, extending the design with the rotation of the building and to the end of the wall, with the logo placed in a distinctive place in harmony with the rest of the design.

Interconnectedness and unity with diversity was achieved despite the large area and its irregularity and despite the presence of door and window openings. However, the viewer's eye sees the painting as completely integrated and large elements pull the eye of the seeker from afar. Thus achieving the advertising and advertising dimension of the village and thus the final design achieved the aesthetic values of coherence and balance in 
the distribution of elements Color balance and a varied dynamic rhythm, taking into account the proportion and proportion between the different design elements.

Modify and develop the design according to the available data from different spaces and window and door openings.

The second mural on the part tongue relied on the large area of the elements to be clearly visible from the shore. Variation of color values from hot to cold with mixing hot colors with the prevailing elements in it cold color such as shark, dolphin and sea dog with the addition of green herbs with a mixed yellow color. Hot color focus in the middle of the mural.

Achieving aesthetic values interconnectedness through the movement of elements and the direction of each element in the direction of the other, and the beginning of the painting. The dolphin, directs the viewer's eye into the interior of the painting, and the shark responds to him in return, directing the eye movement inside the work and moving from crying one part to another in harmony. The direction of the position of the elements from vertical, tilted and wavy, all of this achieved various movement rhythms based on various color rhythms of high color intensity. It depended on the proportion of the elements being large in order to be clear and visible due to the space in front of them to see.

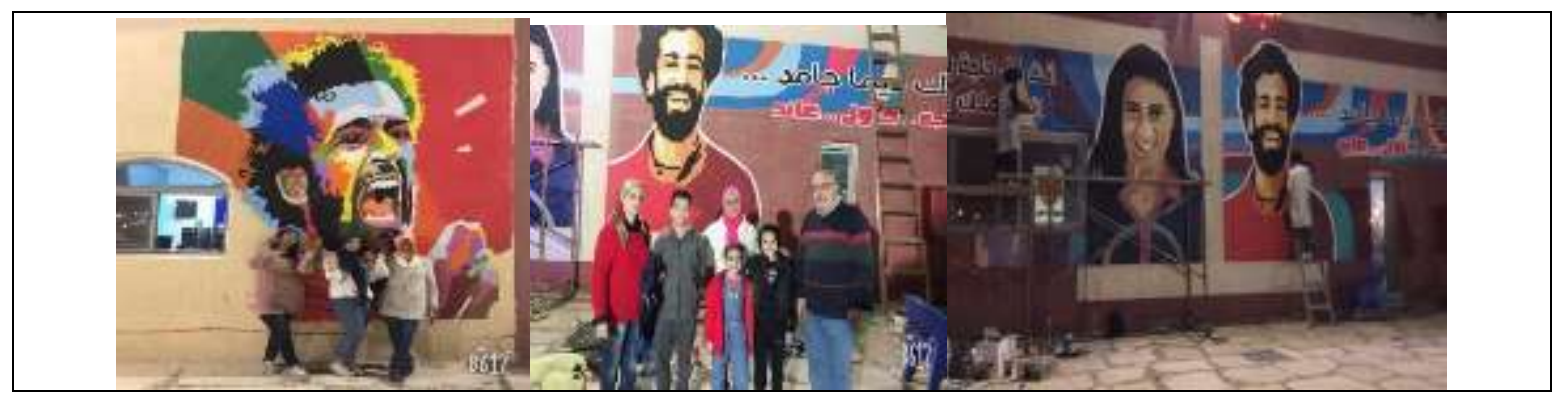




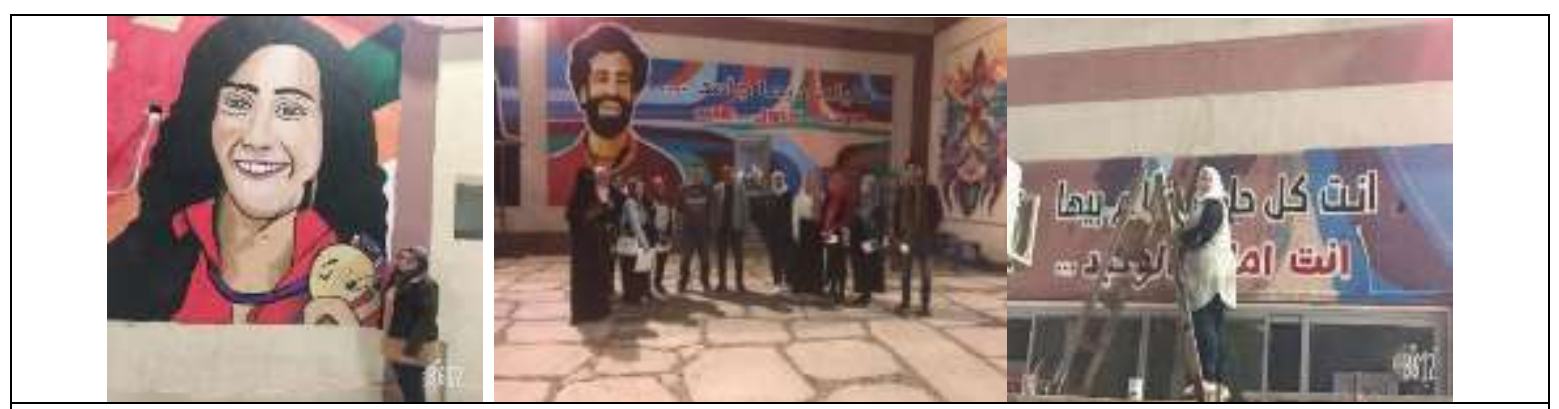

Figure (8) murals, Badr Park

Experiment Five (8)

First: Characterization:

Venue: Social Sports Club (Badr Park)

The Elements: Portraits of International Egyptian Sports Figures - Writings Abstract Symbols

Space: 6 spaces in various places inside the club.

Materials and tools: oil colors - acrylic colors - brushes - thinner.

Number of students: 11 male and female students.

Second: - Determining the positive value learned from the mural (it corresponds to the function of the place, as it is a social athlete, so it was presented as an ideal for young Egyptian world champions in different sports - spreading aesthetic values)

Third: - Initial design planning and specifying design elements drawn from well-known sports figures and there is no dispute over them in terms of their creation and superiority, such as Nour El-Sherbiny, world champion in squash, Farida Othman, world champion in swimming, and Mohamed Salah in football, and the extent of their commitment.

Fourth: Developing its design ideas and various solutions, taking into account the proportions of the place and the level of its height in relation to the architectural site. Next to them, a mural that symbolically abstracted the lion, and the mural on the side door, had to respond to the shape of a girl with Mohamed Salah in a different way. 
. Fifth: - Defining the technical method used as an abstract geometric.

Sixth: - The structural and aesthetic values

- The structural system relied on centralization and enlarging the main element while supplementing the background with a set of geometric areas. Emphasis on hot colors of high intensity, which achieved chromatic coherence and balance through contrasting color distribution and focus on the appearance of various geometric figures and lines that, achieved various rhythms of movement.

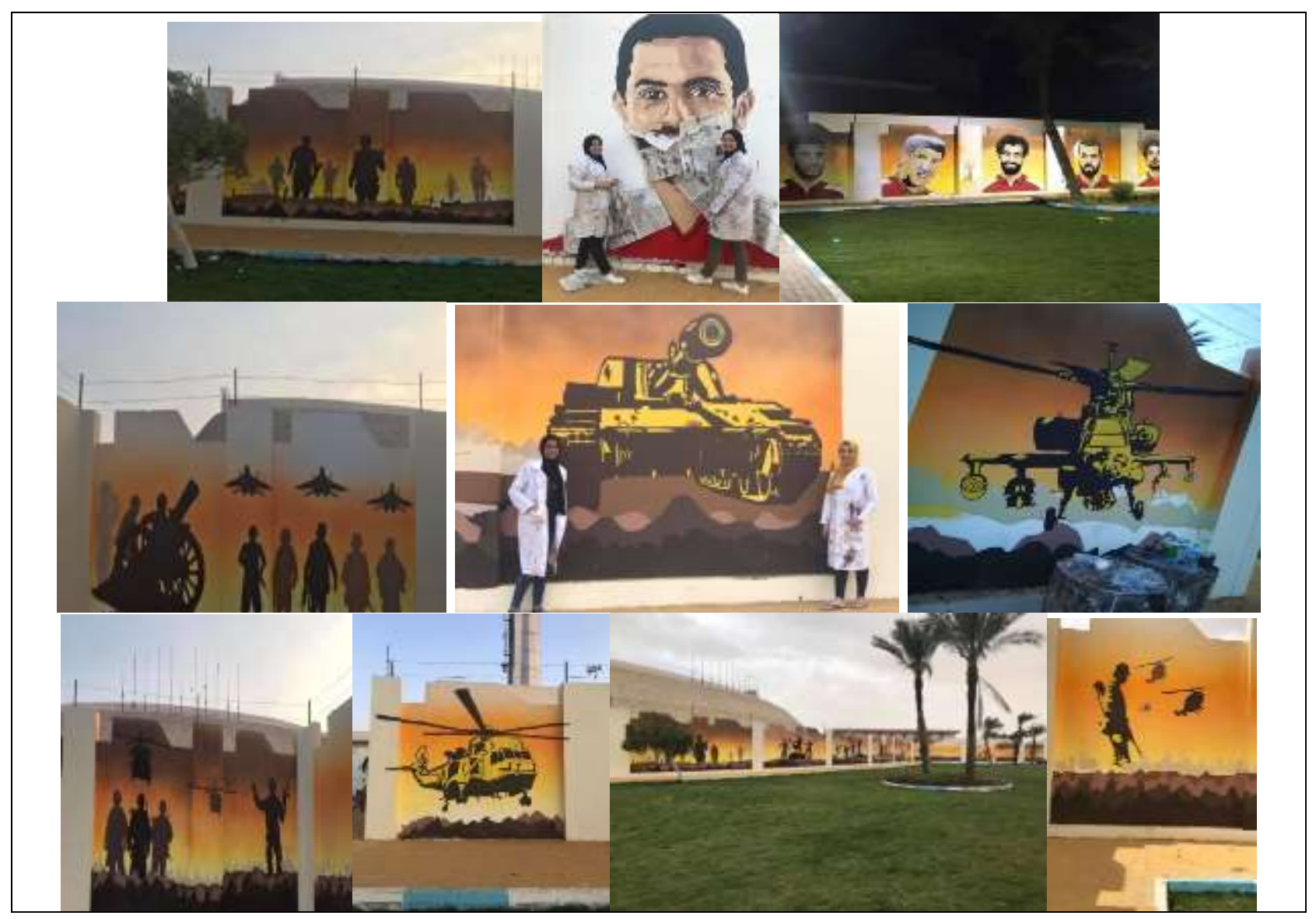



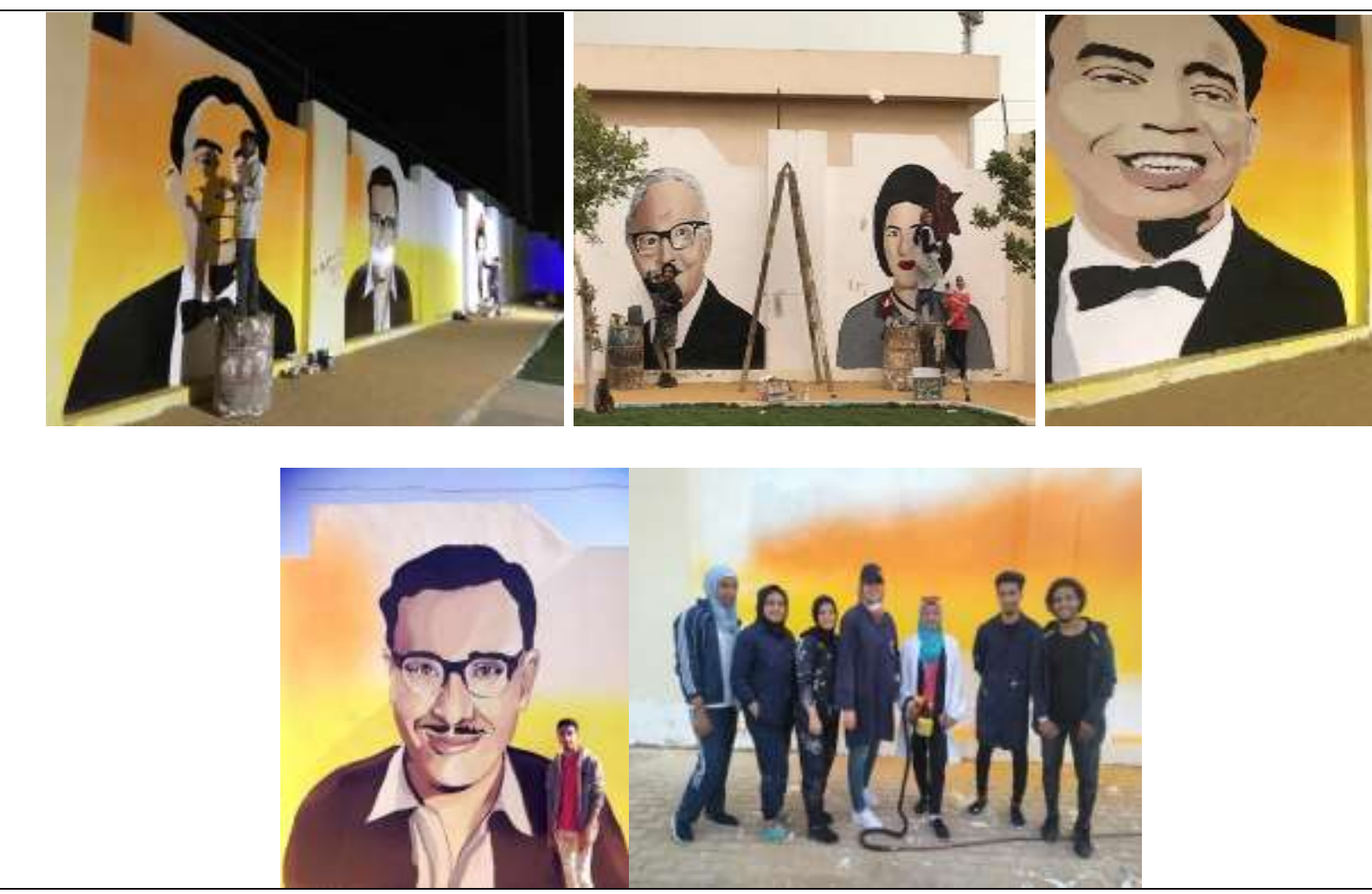

Figure 9: The 900-meter mural of wall of the Suez Stadium

Experiment Six (9)

First: Description:

The place: The Suez Stadium Wall is generally open to the public.

Elements: Well-known figures - silhouettes of military figures, tanks and airplanes.

Area: 900 square meters

Materials and tools: - Acrylic colors - Airbrush - Brushes - Oil and thinner colors.

Number of students: 15 male and female students, 20 assistant students

Second: - Determining the positive value learned from the mural (cultural social - spreading aesthetic values)

Third: - Initial design planning and identification of design elements derived from heritage - socio-historical - from the environment. 
Fourth: - Putting design ideas and various solutions in mind, taking into account the proportions of the place and the level of its height in relation to the architectural site.

. Fifth:- Determining the artistic style used as a symbolic expression.

Sixth: - Evaluating ideas and choosing the ideal solution for what is required. Portraits of the characters of the comedy generation Al-Mawakib were chosen by Ismail Yassin, son of Suez Governorate, as an example of a respectable generation such as the able artist Fouad the engineer and the able artist Abdel Moneim Madbouly

Seventh: - the structural and aesthetic values

The structural system for the design in line with the architectural structure applied to it, the background connects the various design elements.

- The structural foundations used in the design - the juxtaposition and movement of the different elements in directions that transmit the movement of the eye from one to the other as a kind of interconnection between the different elements with the various rhythms of movement.

- Modifying and developing the design according to the data available directly on the mural, especially in the panorama, because placing the elements on the mural achieves a different structure for the artwork than the proposed initial design.

- The final design achieved aesthetic values from interconnectedness with diversity, varied movement rhythms, and balance through the distribution of different elements and color values, taking into account the proportion and proportion in all the different elements and the proportion and proportion between the elements with each other. 


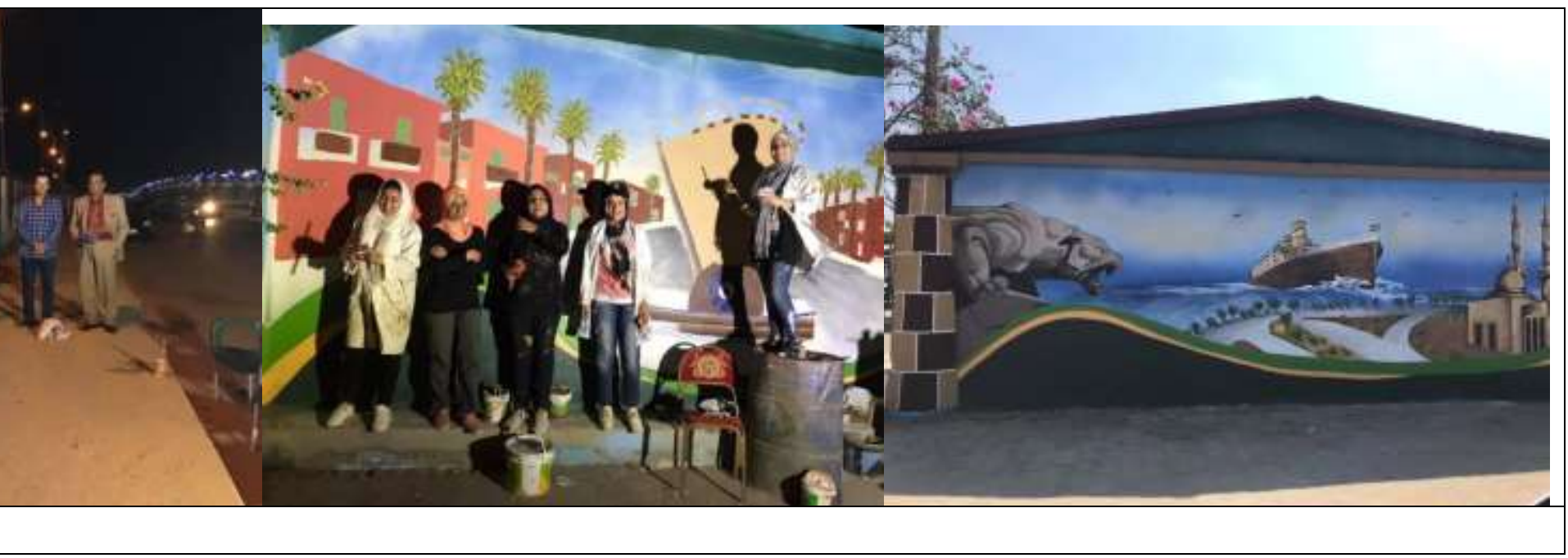

Experiment 8 Figure (11)

First: Description:

Location: The fence of the peace station next to the university

Elements: Elements symbolizing the main landmarks of Suez

Space: 2 bags, each pack is 5 X 6 meters

Raw materials and tools: - Oil colors that brighten the brushes of a variety of sizes

Number of students: 15 students

Second: - Determining the positive value learned from the mural (cultural social - historical in addition to the aesthetic value)

Third: - Initial design planning and identification of design elements derived from heritage and the environment.

Fourth: Developing its design ideas and various solutions, taking into account the proportions of the place and the level of its height in relation to the architectural site. The location of the vision of the wall work at the level of the view and the space available in front of it for the vision extended by the breadth of four streets of a highway and a bridge 
. Fifth - Determining the expressive artistic style.

Sixth: - Evaluating the ideas and choosing the optimal solution for what is required. The design was modified during implementation by making the tiger its direction inside the painting and the difference in the feel of houses in the other painting.

Seventh: - the structural and aesthetic values

- The structural system for designing in line with the architectural structure applied to it depends on the centralization of the part houses in Port Tawfik, and the other part depends on the movement of the elements towards the center.

The structural foundations used in the design are the contiguity between the vertical direction of its collector minaret and the horizontal or tilted direction.

- The final design achieved aesthetic values.

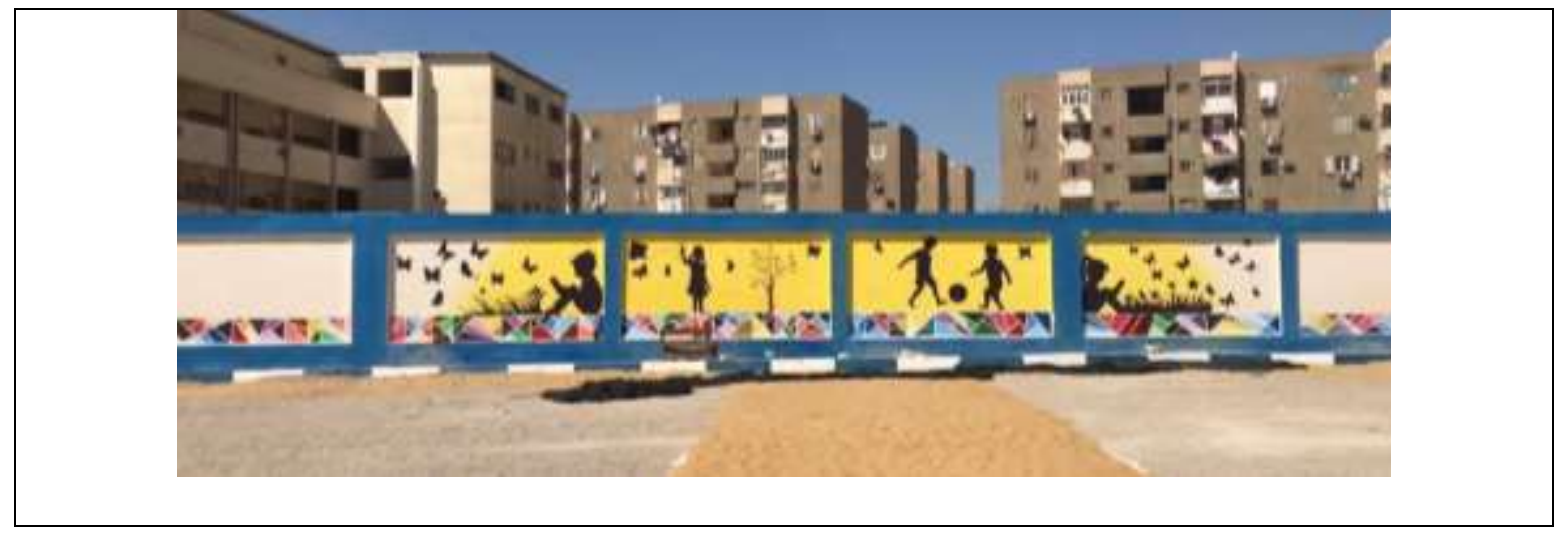




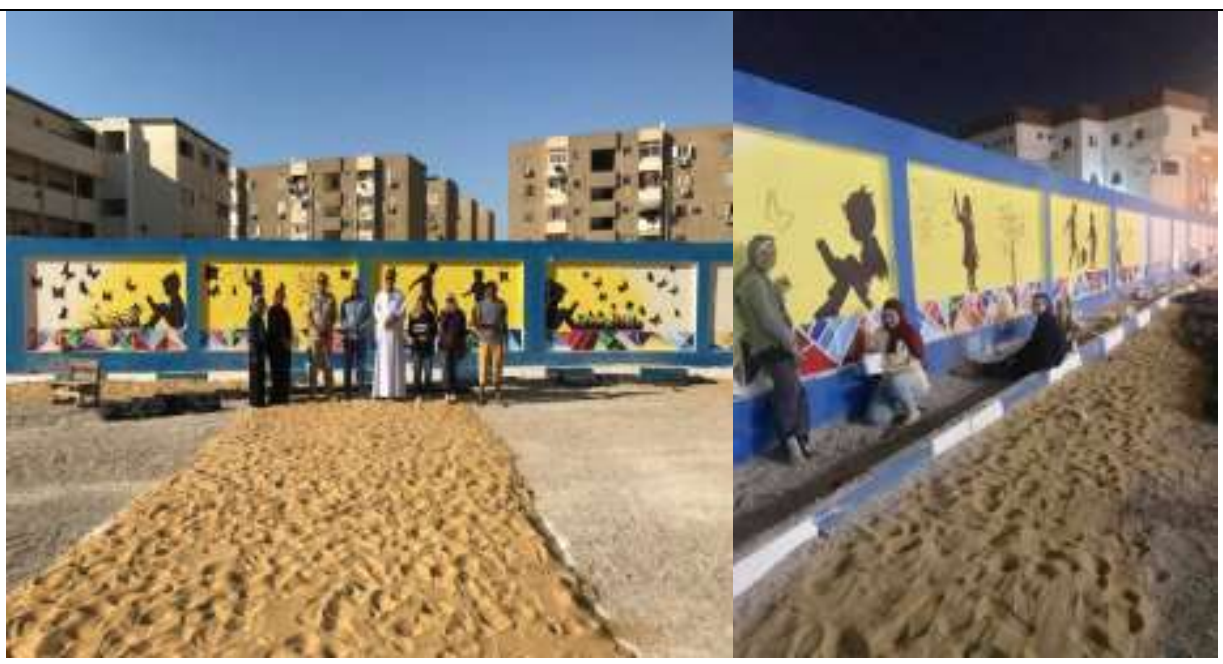

Figure (12) mural of Al-Iman School

The ninth experiment Figure (12)

First: Description: -

The place: the inner wall of the school of faith in Suez.

Elements: Elements that symbolize children

Space: 4 main bags, each $4 * 6$ meter, and 6 packets in each direction.

Raw materials and tools, oil colors, lighten brushes of a variety of sizes.

Number of students: 8 students.

Second: - Determining the positive value learned from the mural (social functional - aesthetic values)

Third: - Initial design planning and identification of design elements derived from the function to be performed for the place.

Fourth: Developing its design ideas and various solutions, taking into account the proportions of the place and the level of its height in relation to the architectural site. The location of the vision of the wall work at the level of view and the space available to it for the vision extended by the breadth of the schoolyard as a whole 
. Fifth: - Defining the artistic style is abstract.

Sixth: - Evaluating ideas and choosing the ideal solution for what is required to achieve the aesthetic function of the place and be in a primary school and KG

Seventh: - the structural and aesthetic values: -

- The structural design system in line with the architectural structure applied to it, depends on the centralization of the two parts in the middle, one symbolizing two children playing soccer and the other for a girl with a kite, then we achieve a semi-symmetry by repeating the shape of a child and his child sitting reading a book next to a tree in the opposite position, which achieved balance with repetition Butterflies in different shapes to achieve the free movement rhythm with a strip of geometric shapes extending the entire length of the wall with high intensity colors, which achieved interconnectedness with the diversity in the artwork. We note the observance of the proportion and proportion of each of the elements used individually or with each other

This, how we find the final design that achieved aesthetic values. 


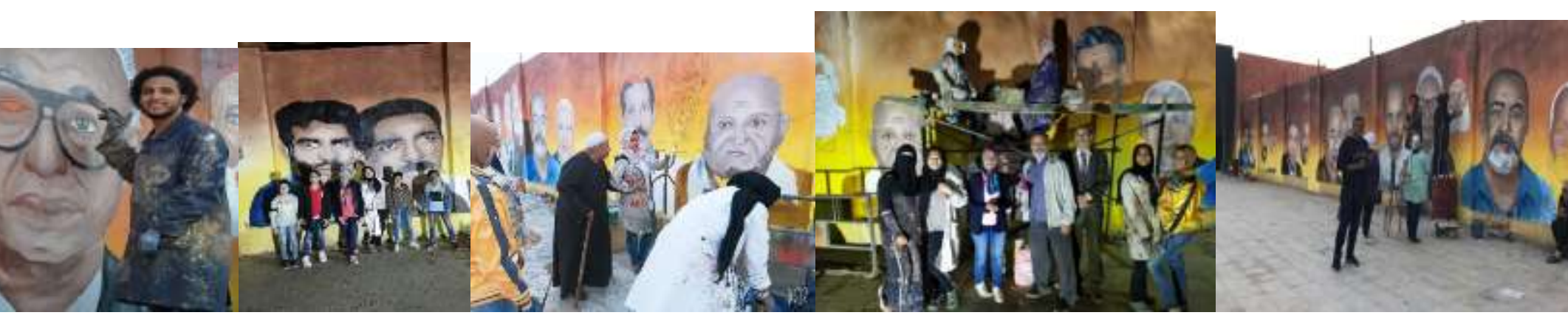

The tenth experiment Figure (13)

First: Description:

Location: Next to Al Swaisa (Suez citizens) Park. 
The elements: Portraits of the martyrs and the Fedayeen of Suez with models of popular resistance figures.

Space: 8 bags, each is $5 \times 6 \mathrm{~cm}$.

Raw materials and tools: - Oil colors, brushes of different sizes, to lighten.

Number of students: 9 male and female students.

Second: - Determining the positive value learned from the mural (cultural social - national - historical in addition to the aesthetic value)

Third: - Initial design planning and determining the distribution of design elements for each category with each other.

Fourth: Developing its design ideas and various solutions, taking into account the proportions of the place and the level of its height in relation to the architectural site, the location of the vision of the wall work in the outlook level, the area along four streets with a planting area in the middle.

. Fifth: - Determine the artistic style used for expression.

Sixth: - Evaluating ideas and choosing the optimal solution for the required overlapping and adjacent elements in a manner commensurate with each other.

Seventh: - the structural and aesthetic values: -

- The structural system for the design in line with the architectural structure applied to it, taking into account that the separations between each cry and the other enter into the design construction, so characters were placed on it mainly in the center of the artwork.

The structural foundations used in the design are the juxtaposition and overlap between the various personalities.

- Modifying and developing the design according to the available data, so the characters 'spaces and placed in relation to the characters next to them were modified. Using high-intensity color values to see them well across the road with the large size of the portraits. 
- The final design achieved aesthetic values of balance and coherence with the diversity of sizes, taking into account the proportion and proportion of portraits and with some, achieving various movement rhythms and emphasizing interconnectedness by unifying the background color

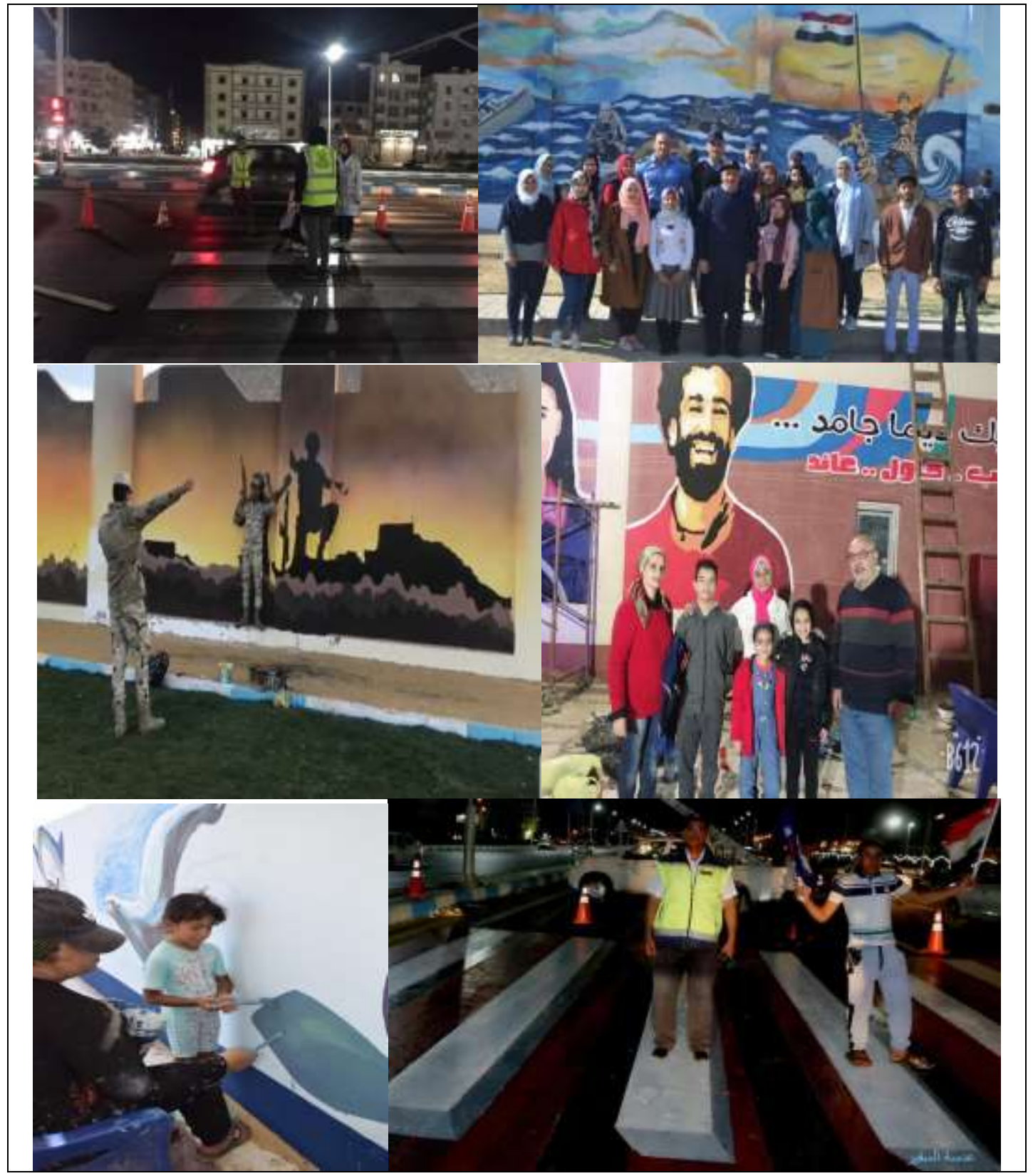




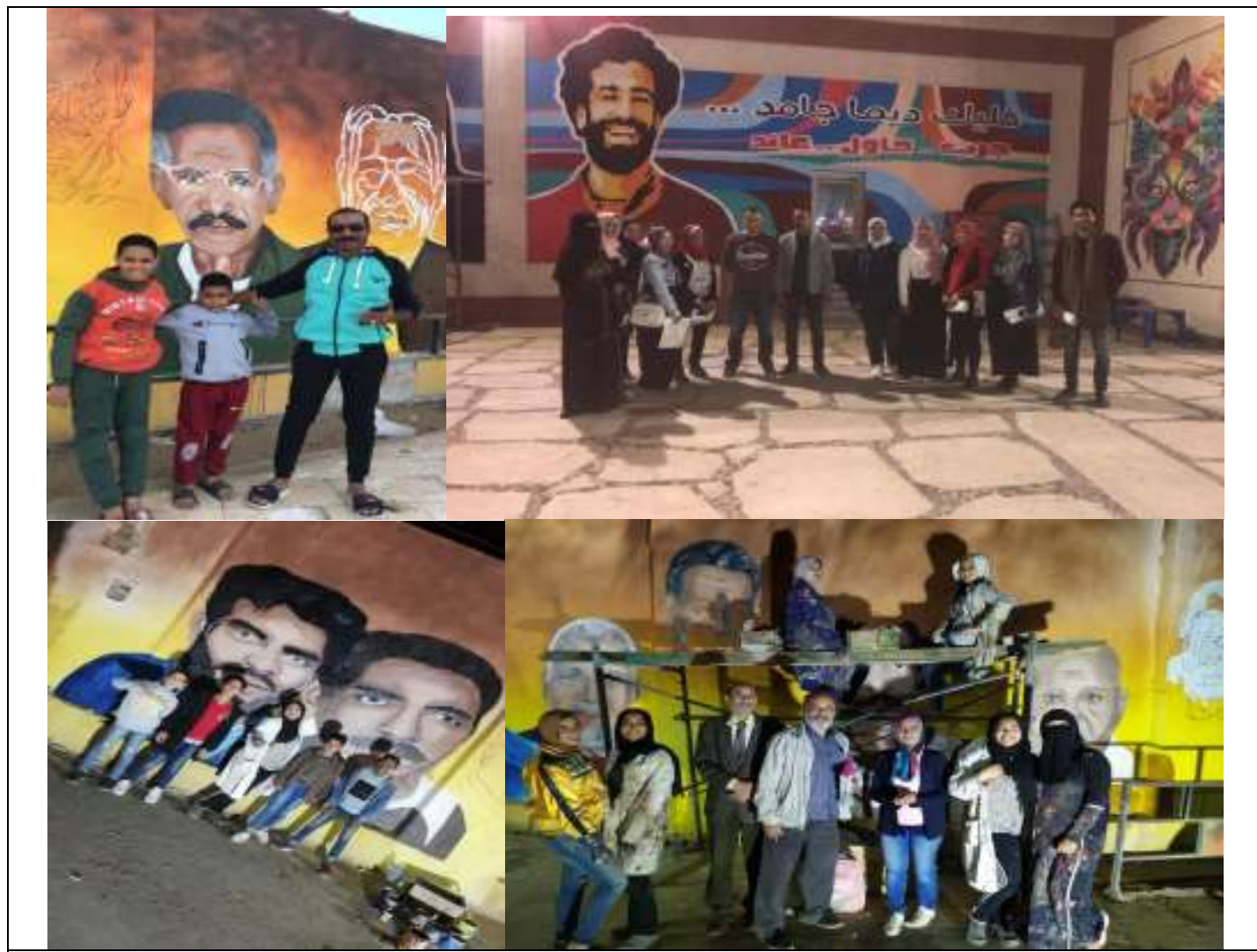

Figure (14) Positive interaction of different categories of society with the murals

Culture for the individual is related to knowledge, but culture for society is related to social characteristics far from being cognitive because it results from the individual and society's perception of science and knowledge in various areas of life.

The term culture here refers to all human knowledge of a society, in addition to that, it is a way of life that distinguishes each human group from the other and is transmitted from one generation to another, as each society has specialized in its own culture that differs from any other society. One society may contain multiple cultures that may be Homogeneous or differentiated, and one of the most important features of culture is that it is human-made and transmitted through him, acquired involuntarily by those who live around him since his birth, whether from the family, neighborhood, 
community or school. Satisfying the needs of man and relieves himself, as it provides him with ready-made solutions that combine all issues. Continuity, as it stems from the existence of the group and their satisfaction with it, in addition to their adherence to it and its transmission from one generation to another and from one community to another, in addition to it being affected, influenced and spread among other nations.

(Culture forms the emotional depth in the life of peoples and nations. If development, in its essence, works to enhance the levels of coexistence among people and advance the lives of individuals in society, then development efforts can never be separated from the cultural formations of society. Culture plays a pivotal role in the development process)

Culture is, in its essence, a dynamic force for change, as it is not static, but rather a continuous state of interaction and permanent harmony based on continuous interactive change in its various levels and elements. People's thoughts, perceptions, outlook, and patterns of response to the world change - much or little - in terms of time and space, and this change includes various forms of cultural expression and its social patterns.

\section{Results}

Obtaining the principle of sustainability is represented in the correct use of heritage, knowledge, environmental and community resources. Culture must be widespread in society because it forms the primary place for social relations between individuals. Culture is the main organizer of the lifestyles and behaviors of community members and their relationship to values related to the environment, history and heritage, and defining the ways in which we interact with the naturalness that surrounds them. Figure no. (14) We notice the interaction of different categories of society, and the development of culture has been achieved equally.

\section{Through the research experience, the results of the research were as follows:-}

\section{1-Aesthetic values:}


The Flower Village Beach mural through the interaction of children of different age categories and their integration with the working category to participate in the implementation of the mural, which achieved the goal of spreading a taste for aesthetic values.

- All the murals have achieved a positive sense of aesthetic values and interaction.

\section{2-National and historical values:}

- The mural of the naval base by shedding light on an important part of Egypt's maritime history and the extent of the strength of the heroes of Egypt and its development through the ages, which enriched the working category themselves, to be themselves a continuous cultural center after their graduation and their transfer to different societies to increasingly transmit knowledge

- The mural of the martyrs and the commandos of Suez had a different cultural developmental impact for all age categories including children in schools. The names of martyrs or the sons of Suez themselves from the head of his family to tell his wife and children about the martyrs or the elder and their remembrance of events and their grandchildren to see the heroes. So the stories of the championships were renewed for university and high school youth And their sense of the rest of Suez and its importance for its heroes.

- Al-Swaisa (Suez citizens) mural with the display of the different classes of the army, aircraft and tanks, which affected the recruits and their feeling that this is a kind of honor for every Egyptian

\section{3- Values of ideals and a culture of persistence and challenge: -}

Badr Park Club and Al-Swaisa mural by displaying respected models that have an imprint in society and by displaying models of Egyptian champions, girls and youth, who have become world champions with outstanding athleticism and morals. 
4-. Preserving the historical, societal and aesthetic environment and reusing it appropriately contributes to improving the quality of life of its residents in many ways. It enhances their sense of belonging and social cohesion, and provides an enjoyable environment for the spread of beauty values.

5- Shedding the important light on the murals that seek to spread culture and creativity, and achieve various cultural values based on heritage, for the sake of sustainable development.

6-. There is a positive relationship between the constructive values of murals design derived from heritage and developing the culture of societies.

7- There is a positive relationship between the content and content of the murals design and the development of mutual culture between different societies.

8-. Developing the culture of society through the constructive values of murals design derived from the heritage

9-. The structural systems of murals derived from heritage achieve sustainable development of the society's culture.

10- . Highlight the importance and gravity of the role that street murals play in shaping the awareness of the recipient.

11- The ability to cross street murals as a visual language to establish a dialogue with different types of society.

\section{Recommendations: -}

1- Paying attention to the issue of street murals, being the biggest influence on sustainable cultural development for different members of society.

2- Emphasis on linking aesthetic values with heritage, history and their relationship to tourism.

3- Emphasis on empirical research that links art and the development of ideals.

4- History as a source for mural design. 


\section{References: -}

1- Prof. Dr. Rasha Mohamed Ali-. Prof. Hajar Saeed Ahmed - Instructor at the Faculty of Applied Arts - Designer / Hala Mohamed Ahmed Omar Activating the morpho theory in designing contemporary glass murals Journal of Architecture and Arts, No. 8.

2- Ali - Assaad Watqa - Article on Culture and Sustainable Development: What Relationship? - College of Education - Kuwait University - AlMuthaqaf newspaper - Issue 5352, Saturday 1/5/2021 AD http://ns1.almothaqaf.com/a/qadaya/939134

3- Youssef Abdel Rahman, Buthaina, a new artistic vision for murals inspired by Islamic thought, $\mathrm{PhD}$ thesis, Helwan University: Faculty of Applied Arts, 1987 AD.

4- Bismarck, Ehab, Aesthetic and Structural Foundations of Design (The Effectiveness of Formal Elements) for the Beginner of Study in the Fields of Art and Design, Part One, the Egyptian Writer for Printing and Publishing, 1992.

5- Bakri, Mohamed, The Organic Recruitment of the Prominent and the Recessed Surface in Contemporary Egyptian Painting, Ph.D. Thesis, Helwan University: Faculty of Art Education, year 2000 AD

6- Shaheen, Asmaa, a new artistic vision for employing the structural foundations of Islamic organic decorations as an introduction to plastic and structural formulations in decorative design. Ph.D. Thesis, Ain Shams University: Faculty of Specific Education, 2007 AD.

$7-$

http://islamicart.museumwnf.org/database_item.php?id=monument;isl;pa;m on01;15; ar Mural painting... The first visual language known to man - he found in it a haven for self-expression and existential questions - Monday March 2, 2020 14:19 
INTERNATIONAL JOURNAL OF MULTIDISCIPLINARY STUDIES IN HERITAGE

\section{RESEARCH}

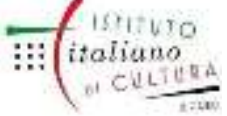

ISSN: 2785-9622

VOLUME 3, ISSUE 2, 2020,69-103.

www.egyptfuture.org/ojs/

$8-$

https://mjaf.journals.ekb.eg/article_21573_acf71cae0c7e7ecd0e45cf8f0b88a bbd.pdf

Received: October 2020

Accepted: December 2020 